\title{
A EDUCAÇÃO TÉCNICA A PARTIR DO DIAGNÓSTICO CRÍTICO DA MODERNIDADE DO FILÓSOFO ALEMÃO MARTIN HEIDEGGER
}

\author{
Poliana Emanuela da Costa ${ }^{1}$ \\ Silvana Maria Santiago ${ }^{2}$
}

\section{Resumo:}

Este artigo objetiva pensar a educação técnica a partir do diagnóstico crítico que o filósofo alemão Martin Heidegger realiza sobre a "era da técnica". Desse modo, para aproximar o tema da educação da filosofia de Heidegger, mais precisamente no que tange à questão supracitada, utilizaremos, basicamente, os seguintes textos: educação profissional: crise e precarização (2019) e escritos fundamentais do pensador alemão que tratam a fundo da temática da técnica. São eles: A questão da técnica (2008), Que é Metafísica? (1983) e O fim da filosofia e a tarefa do pensamento (1983). Esses textos servirão de fio condutor para refletirmos sobre alguns desafios da educação tecnicista. O entrecruzamento dessas reflexões nos permitirá compreender, a partir de Heidegger, como a questão da técnica, assim como a tecnologia, vão muito além das suas configurações instrumentais, ultrapassando, em grande medida, o sentido neutro dos avanços tecnológicos, atribuindo ao conhecimento um caráter, sobretudo, pragmático. Desta feita, esse artigo procura contribuir para pensarmos a educação em sentido mais amplo, não apenas no que diz respeito às transformações técnico-científicas, mas, sobretudo, uma educação reflexiva, questionadora e transformadora efetiva da sociedade.

Palavras-Chave: Educação; Educação técnica; Técnica moderna; Heidegger; Ontologia.

\section{TECHNICAL EDUCATION FROM THE CRITICAL DIAGNOSIS OF MODERNITY OF THE GERMAN PHILOSOPHER MARTIN HEIDEGGER}

\begin{abstract}
:
This article aims to think about technical education from the critical diagnosis that the German philosopher Marin Heidegger makes about the Age of Technique. Therefore, in order to bring the issue of education closer to Heidegger's philosophy, precisely regarding this theme, we will essentially focus on the following texts: Professional Education: crisis and precariousness (2019) and the fundamental writings from the German thinker which deal profoundly with the thematic of technique, as follows: The question of technics (2008), What is Metaphysics? (1983) and The end of philosophy and the task of thinking (1983). These underlying texts will conduct a thorough reflection on some paths of technicist education. These intersecting reflections will allow us to understand from Heidegger's perspective how the issue of technique, as well as of technology, goes far beyond its instrumental configurations, largely surpassing the neutral sense of technological advances and giving knowledge a character predominantly pragmatic. Hence, this article aims to contribute to a reflection on a broader sense of education, not only concerning technical and scientific transformations, but most importantly a reflexive, questioning and effectively transforming education of society.
\end{abstract}

Keywords: Education; Technical Education; Modern technique; Heidegger; Ontology.

1 Docente do Instituto Federal de Educação, Ciência e Tecnologia do Ceará. Mestra em Filosofia pela Universidade Federal do Rio Grande do Norte - UFRN (2014). Possui especialização em Educação, na área de Currículo e Ensino (UERN/2010). Graduada em Licenciatura em Filosofia pela Universidade do Estado do Rio Grande do Norte (UERN/2007). E-mail: poliana.costa@ifce.edu.br. http://orcid.org/0000$\underline{0002-9652-8349}$

2 Graduada e Mestra em Filosofia. Doutora em Educação pela Universidade Federal do Ceará. Professora da Universidade do Estado do Rio Grande do Norte. Área de atuação: Educação e Filosofia. E-mail: silvanamariasantiago@yahoo.com.br. http://orcid.org/0000-0002-4090-5264 
Podemos afirmar, em linhas gerais, que a educação profissionalizante no Brasil não é um fenômeno novo. Desde o Brasil Império, havia a preocupação do governo em promover algum tipo de ocupação àquelas pessoas, mais especificamente às crianças, que viviam em estado de vulnerabilidade nas ruas. Essa preocupação ampliou-se após a proclamação da República, em 1889, com a criação e a manutenção de instituições de ensino como os Liceus, cujos investimentos tinham o intuito de educar e assegurar à população mais carente algum tipo de independência e dignidade (MANFREDI, 2002).

Ao longo do tempo, o ensino profissionalizante foi ganhando diversas configurações e contornos. A manutenção e os investimentos nas escolas técnicas, além do processo de urbanização e da criação de fábricas, ganharam maior importância como política pública brasileira a partir de 1930, na chamada Era Vargas. É justamente a partir da sua concepção enquanto política pública que o ensino profissionalizante passou a ser objeto de interesse político mais amplo, pois via-se na educação tecnicista não somente uma forma de preparar os indivíduos para o mundo do trabalho, mas sobretudo, como mecanismo para a manutenção do domínio de uma classe sobre outra.

O esboço histórico que realizamos sobre a educação profissional nos permitiu chegar às questões que, de fato, nos interessam neste artigo, ou seja, qual é a importância da técnica e da tecnologia para o campo educativo? Como a educação técnica atua na transformação social? Para esclarecer essas indagações, propomos uma aproximação entre as reflexões de autores como Martin Heidegger (1983-2008), Deribaldo Santos (2019) e outros pensadores. Não se trata de uma escolha aleatória, mas ao dialogar com o livro: educação profissional: crise e precarização (SANTOS, 2019) foi possível discutir acerca das lacunas da educação moderna e contemporânea, bem como rever as concepções sobre técnica e tecnologia como instrumentos de poder que atuam intencionalmente para a manutenção da desigualdade social no nosso país. Por outro lado, essa reflexão não seria possível se não compreendermos a fundo o que é a técnica e como esta se desdobra até sua configuração como tecnologia, problematizando qual é o resultado desse avanço para a sociedade.

O filósofo alemão Martin Heidegger, realizou uma análise profunda sobre a questão da técnica na sociedade atual. Entre outros aspectos, demonstrou em seus escritos todo o caráter intencional de manipulação da subjetividade humana e, por conseguinte, as transformações causadas pelos dispositivos tecnológicos na sociedade moderna e que reverberam, inevitavelmente, no mundo contemporâneo.

\begin{tabular}{|c|c|c|c|c|}
\hline Q Rovista Dialeatus & Ano 10 & n. 23 & Maio - Agosto 2021 & p. $267-278$ \\
\hline
\end{tabular}


Em um primeiro momento, associado às mudanças de concepção na educação técnica, o que mais fica evidente no mundo moderno são as novas configurações do que compreendemos pela ideia de trabalho. De acordo com Santos (2019), parafraseando Marx, o ser humano retira da natureza as fontes necessárias para sua existência material. O trabalho é o ato fundante do ser social (SANTOS, 2019, p.28). Desse modo, percebemos que a interação do homem com a natureza é intencional. Assim, é importante destacar que existem diversos mecanismos que orientam as práticas humanas na sua lida com a natureza, como exemplo, os diversos espaços coletivos (políticos, religiosos, entretenimento) nos quais os sujeitos estão inseridos. No entanto, é a partir da educação formal que o ser humano constrói, mais especificamente, seu modo de atuação sobre a natureza e a sociedade. De acordo com Santos:

\footnotetext{
O trabalho, ao fundar o ser social, entretanto, não esgota toda a potencialidade humana. Serão necessários outros complexos sociais para que o devir humano se desenvolva. A educação é um desses complexos potencializadores do desenvolvimento humano. (SANTOS, 2019, p. 28).
}

Ainda nesse contexto, Santos (2019) parafraseia Lukács ao afirmar que o trabalho possui uma dependência ontológica com a educação. Essa relação ontológica é o que permite pensarmos educação e técnica, sobretudo, a partir de uma perspectiva heideggeriana. Heidegger não escreveu propriamente sobre a educação, mas era evidente sua preocupação com os rumos da universidade em meio ao progresso técnico. Heidegger temia que o pensamento dentro do espaço universitário se reduzisse tão somente às diretrizes instrumentais e utilitárias e que os estudantes esquecessem seu verdadeiro papel enquanto sujeitos reflexivos e problematizadores. Para Heidegger, a era da técnica moderna caracteriza a supremacia do ente sobre o ser, ou seja, do mundo dos instrumentos em relação ao pensamento. Nas palavras de Heidegger:

\footnotetext{
Basta apontar para a autonomia da Psicologia, da Sociologia, da Antropologia Cultural, para o papel da lógica como Logística e Semântica. A filosofia transforma-se em ciência empírica do homem, de tudo aquilo que pode tornarse objeto experimentável de sua técnica, pela qual ela se instala no mundo, trabalhando-a das múltiplas maneiras que oferecem o fazer e o formar. Tudo isso realiza-se em toda parte com base e segundo os padrões da exploração científica de cada esfera do ente (HEIDEGGER, 1983a, p. 72).
}

Essa preocupação com o progresso técnico para a formação humana também caracteriza sobremaneira a discussão proposta por Santos (2019). O autor, através da

\begin{tabular}{|l|l|l|l|l|}
\hline Rovista Dialectus & Ano 10 & n. 23 & Maio - Agosto 2021 & p. $267-278$ \\
\hline
\end{tabular}


abordagem do pensamento de Marx, trabalha com a perspectiva de omnilateralidade ${ }^{3}$ como proposta fundamental para a formação humana, de modo que contemple as mais variadas dimensões cognitivas possíveis. Uma formação omnilateral propõe desenvolver um ser humano crítico e, sobretudo, consciente de si e de sua realidade social. Percebemos nesse sentido, que a influência da técnica moderna na educação, principalmente na educação profissional, se constitui como um eixo articulador de diversos pensadores de diferentes abordagens teóricas.

Santos (2019) realiza uma análise sobre o percurso histórico da educação profissional à luz das contribuições reflexivas de Ivo Tonet, Marx, Manacorda e Luckás. Esses pensadores apresentam, em suas discussões, fortes influências do pensamento de Marx. Uma das questões tônicas desses pensadores é o tema da educação. De modo geral, entendem que a educação proposta no seio do capitalismo é uma educação fragmentada e instrumental que prepara o indivíduo para ocupações repetidas e utilitárias. Assim, constitui-se um tipo de educação que perde o sentido de si mesma. Resta compreender porquê a técnica, ao invés de contribuir para uma perspectiva de educação mais integradora do ser humano e do mundo, contribui contrariamente para que o homem perca a si mesmo em meio aos objetos que manipula.

A compreensão pode ser dada a partir da leitura de Martin Heidegger, em especial, daquilo que diz respeito à análise que o filósofo realiza sobre a questão da técnica. Para Heidegger, a técnica moderna nada mais é do que a consumação da metafísica, ou seja, o domínio do ente sobre o ser. Em sentido outro, a técnica moderna se configura como uma realidade em que toda a natureza é codificada e catalogada para tornar-se um ente passível de ser calculado. O ser, enquanto abertura e mistério histórico é esquecido em prol da previsibilidade matemática de tudo o que existe. Heidegger afirma que a essência da técnica repousa na com-posição (2008, p. 28). A com-posição é, nesse caso, a força motriz que faz com que o ser humano queira explorar, ser o dono absoluto da natureza, manipulando-a conforme suas necessidades pessoais. Nas palavras de Heidegger: "A essência da técnica moderna repousa na com-posição. A com-posição pertence ao destino do desencobrimento (...)" (HEIDEGGER, 2008, p. 28). O

O conceito de omnilateralidade é utilizado por Marx, não de forma a ter uma única definição, mas seu sentido geral contribui para a reflexão em torno do problema da educação no pensamento do autor. Ele se refere a uma formação humana oposta à formação unilateral provocada pelo trabalho alienado, pela divisão social do trabalho. Trata-se não somente de uma perspectiva ontológica sobre o trabalho, mas de compreender o trabalho dentro da esfera política e histórica.

\begin{tabular}{|l|l|l|l|l|}
\hline Govista Dialectus & Ano 10 & n. 23 & Maio - Agosto 2021 & p. 267 - 278 \\
\hline
\end{tabular}


desencobrimento acontece por meio da exploração: “Com-posição é a força de reunião daquele "por" que im-põe ao homem des-cobrir o real, como dis-ponibilidade, segundo o modo da com-posição.” (HEIDEGGER, 2008a, p. 27).

Concebendo a técnica moderna como a consumação do cálculo, da natureza convertida em ente passível de manipulação e previsibilidade, Heidegger mostrava-se aflito com o destino da universidade, com a educação técnica que estava sendo ofertada. O filósofo compreendia que, muito além da modernização dos meios pelos quais se adquire conhecimento, estava a dissolução do pensar crítico e reflexivo. Estava em jogo a questão ontológica, isto é, o sentido da existência humana para além da exploração e do cálculo. É diante dessa perspectiva que a técnica se apresenta nociva para a educação, pois olhar técnico do ser humano sobre a natureza se configura, antes de mais nada, como o domínio do homem sobre o mundo, na perspectiva da exploração ilimitada.

Heidegger apontava a cibernética como ciência principal de controle dos sistemas científicos e afirmava ainda que essas ciências orientariam e teriam o controle de toda a sociedade, inclusive do trabalho humano. A formação dos sujeitos teria como aspecto basilar o conhecimento técnico. A relação do ser humano com a natureza se daria a partir da ótica da dominação e da exploração e, nesse percurso, o próprio ser humano se transformaria em um instrumento de uso. Nas palavras de Heidegger:

\footnotetext{
Esta ciência corresponde à determinação do homem como ser ligado a práxis na sociedade. Pois ela é a teoria que permite o controle de todo o planejamento possível e de toda organização do trabalho humano. A cibernética transforma a linguagem num meio de troca de mensagens. As artes tornam-se instrumentos controlados e controladores da informação. (HEIDEGGER, 1983a, p. 72).
}

Sabemos que um dos caminhos mais viáveis para a edificação do pensamento técnico de forma sistemática é a educação. É ela quem conduz, em grande medida, o modo como enxergamos o mundo. As diretrizes tecnológicas para o ensino preveem a unilateralidade do conhecimento. Esse conceito que encontramos na obra de Marx e que é desenvolvido por Santos (2019) aponta para a mesma inquietação presente nas reflexões de Heidegger no que diz respeito à formação humana. De um lado, há a preocupação com o trabalho que precisa acompanhar o desenvolvimento tecnológico. As escolas politécnicas e as escolas de ensino profissional, no entanto, não podem utilizar a educação como instrumento de polarização social. Para uns, é ofertada uma formação, cujo progresso técnico é também acompanhado do conhecimento sobre as

\begin{tabular}{|c|c|c|c|c|}
\hline Q Rovita Dialeatus & Ano 10 & n. 23 & Maio - Agosto 2021 & p. $267-278$ \\
\hline
\end{tabular}


ciências. Nesse caso, o estudante e futuro trabalhador consegue perceber o objetivo e o sentido do seu trabalho, enquanto para outros é ofertada uma formação fragmentada. Diante dessa perspectiva, o progresso técnico não fornece meios para que o sujeito possa pensar em si mesmo como agente transformador da sociedade. Contrariamente a essa ideia, a técnica restringe os campos cognitivos do estudante fornecendo-lhe uma educação utilitária sem um viés crítico da sua realidade social. De acordo com Santos:

\begin{abstract}
No que se refere ao processo educacional que possa formar omnilateralmente, deve-se considerar um sistema educativo preocupado em restabelecer o vínculo afetivo (prazer nos bens que se produz) com a atividade intelectual e seus fundamentos científicos não somente de forma passiva, mas como o resultado do trabalho, o que demandaria a colaboração entre educação intelectual, do corpo e das capacidades tecnológicas possibilitadas pelo devir humano, além de contemplar a esfera espiritual. Nesse processo, os trabalhadores são considerados igualmente em sua totalidade, adquirindo consciência e autoconsciência de suas intenções e finalidades. Conectados ao ser genericamente humano universal, exercem também a práxis revolucionária de unir teoria e prática na ação de transformar a natureza. (SANTOS, 2019, p. $67)$.
\end{abstract}

A citação nos permite retomar o pensamento de Heidegger no que tange a sua preocupação com os rumos da universidade, principalmente por volta de 1930, com a intensificação do progresso técnico-científico. A crítica de Heidegger nesse contexto não se dá exatamente pelo espanto diante dos dispositivos tecnológicos, tampouco por se tratar de um pensador saudosista que recusa a todo custo o progresso da técnica moderna. Antes, Heidegger se coloca como crítico ferrenho da técnica moderna como propulsora irrefreável de um saber utilitário e, portanto, desagregadora da cultura e do sentido de “comunidade." O filósofo alemão via na universidade um espaço onde a filosofia poderia florescer e se desenvolver enquanto experiência filosófica. Desse modo, era dever do pensamento filosófico refletir sobre os rumos da universidade em meio ao ensino tecnicista.

Segundo Alexandre Franco de Sá em seu livro intitulado Heidegger e a essência da universidade (2008), o filósofo alemão realiza uma crítica ao modo como as disciplinas são organizadas dentro das universidades. Segundo Heidegger, as ciências não dialogam entre si permanecendo como saberem estanques e socialmente úteis. A questão aqui não é o predomínio das ciências dentro das universidades, mas é justamente o fato de não encontrarmos também um sentido teórico e fundamentado para essas ciências. Um sentido que corresponda também ao âmbito crítico e questionador de si mesmo e não somente às determinações cotidianas práticas e utilitárias. Vejamos:

\begin{tabular}{|c|c|c|c|c|}
\hline Q Rovita Dialeatus & Ano 10 & n. 23 & Maio - Agosto 2021 & p. $267-278$ \\
\hline
\end{tabular}


Esta variedade estilhaçada de disciplinas só é hoje mantida em conjunto através da organização técnica das universidades e faculdades, sendo-lhe só atribuído um significado através do estabelecimento prático de fins das especialidades. Em contraposição a isso, o enraizamento das ciências no seu fundamento essencial morreu. Dispersando as disciplinas universitárias em função da sua utilidade e da sua organização técnica, isolando essas mesmas disciplinas, desenvolvendo-as a partir de eventos em que se reproduz aquilo que se diz, o falatório retira à universidade aquilo que constitui o núcleo da sua atitude teórica. (FRANCO, 2008, p. 18-19).

De acordo com Franco, trata-se de uma crítica de Heidegger ao caráter de mera reprodução de um saber que já está constituído tecnicamente. A preocupação de Heidegger com os rumos da universidade diz respeito ao fato de esta transformar-se em espaço de reproduções tecnicistas desvinculadas de um saber científico teórico mais robusto. Heidegger questiona a falta de inquietação dos jovens universitários, a falta de autenticidade dos seus pensamentos e, portanto, a falta de criatividade. O conhecimento científico é o que permite compreendermos como podemos e devemos atuar no mundo, o entrecruzamento dos diversos componentes curriculares de modo a demonstrar, de fato, sua relação intrínseca com uma dimensão mais ampla do conhecimento. Contrariamente a essa ideia, as inúmeras disciplinas, sejam nas universidades, nos institutos ou nas escolas profissionalizantes, levam à reprodução tecnicista do conhecimento e, portanto, ao seu atrofiamento.

Não obstante, sabemos que essa divisão, saber teórico/técnico, não é de modo algum uma polarização neutra, mas sempre manteve uma intencionalidade. Sua intencionalidade consiste em dividir a sociedade. De um lado, formar aqueles que possuem maior capacidade epistemológica em detrimento daqueles que possuem um saber operacional. A proposta de ensino tecnicista é um dos pilares que sustenta a desigualdade social. Se fôssemos realizar um apanhado histórico sobre essa questão, veríamos que, de acordo com Santos (2019), o ensino propedêutico, ou seja, o ensino das ciências, das letras e das artes era destinado aos senhores burgueses para que eles pudessem continuar a ocupar seu lugar de mando:

É nesse quadro que brotam os dois modelos paralelos e distintos de educação sistematizada - mas articulados entre si -, dos quais a burguesia retira sua solução para o dilema trabalho-instrução. Isto é, com base no complexo educativo em sua vertente stricto, surge um modelo destinado à classe senhorial, que preferimos denominá-lo de ensino propedêutico, clássico e científico, cuja organização curricular carrega ensinamentos das ciências, das letras, das artes da oratória, entre outras disciplinas voltadas à formação dos dirigentes e seus prepostos; e outro modelo destinado aos indivíduos que ocuparão os postos da produção material da sociedade propriamente dita, os trabalhadores. A esse restrito ramo de uma educação específica, que, por sua

\begin{tabular}{|l|l|l|l|l|}
\hline Govista Dialectus & Ano 10 & n. 23 & Maio - Agosto 2021 & p. 267 - 278 \\
\hline
\end{tabular}


vez, se desprende - estando sempre vinculada a ela - da educação voltada a resolver demandas próprias de uma sociedade de classes antagônicas, denominamos de ensino profissionalizante, direcionado aos imperativos práticos, cujo conteúdo curricular prioriza as técnicas quase artesanais, apreendidas nas oficinas. (SANTOS, 2019, p. 46-47).

Diante do breve apanhado histórico sobre a educação tecnicista, ratificamos que a aplicação das técnicas na educação é extremamente intencional. Sua intenção é justamente sobrepor ou dicotomizar a prática da teoria e, com isso, reproduzir um modelo de sociedade onde uns têm acesso ao conhecimento científico e outros ao conhecimento prático. Por outro lado, é importante destacar que o problema não é o estudante aprender um ofício, muito pelo contrário, é o trabalho qualificado garante ao indivíduo sua dignidade e sobrevivência, bem como sua satisfação pessoal. O que está em jogo é que para esses estudantes é apresentada uma faceta da técnica como se esta constituísse um fim em si mesma, como se a natureza e a sociedade fossem um todo operacional que prescindem do pensamento crítico. O progresso técnico encontra sua raiz, como afirma Heidegger (2008), na consumação do próprio ente.

É a partir do aprofundamento sobre o que é técnica moderna que podemos compreender a razão pela qual não podermos tratá-la como sendo simplesmente uma modernização de instrumentos e dispositivos que facilitam nossa vida. O engenhoso processo da técnica e sua evolução enquanto tecnologia aponta para direcionamentos muito bem definidos. A técnica moderna como a conhecemos, ou seja, um meio para um fim, não corresponde ao que Heidegger denomina como essência da técnica. Vejamos o que o pensador afirma em seu texto, "A questão da técnica" (2008):

A técnica, não é, portanto, um simples meio. A técnica é uma forma de desencobrimento. Levando isso em conta, abre-se diante de nós, todo um outro âmbito para a essência da técnica. Trata-se do âmbito do desencobrimento, isto é, da verdade. (HEIDEGGER, 2008a, p. 17).

A técnica em sua característica instrumental nos conduz a pensar que se trata de uma intervenção neutra na natureza e na sociedade. Mas a outra faceta da técnica moderna é aquela que corresponde ao predomínio da subjetividade humana como senhora absoluta que adequa a natureza à representação dos desígnios da racionalidade técnicocientífica. Essa adequação não se restringe a uma esfera particular da vida ou a um campo profissional específico. A técnica enquanto objetificação do mundo é um projeto que se inicia, segundo Heidegger, com os gregos e culmina na modernidade, cujo principal objetivo é a edificação de um tipo de racionalidade que concebe todos os outros entes

\begin{tabular}{|l|l|l|l|l|}
\hline Q & Ano 10 & n. 23 & Maio - Agosto 2021 & p. 267 - 278 \\
\hline
\end{tabular}


existentes como fonte de recurso ou reserva. A racionalidade técnica que se aprimora na modernidade vê na educação um eixo articulador de propagação, sistematização e legitimação de suas ideias.

Um dos exemplos mais marcantes para o processo de disseminação da racionalidade técnica foi a revolução industrial iniciada no século XVIII. A partir dali, a formação humana através das disciplinas propedêuticas dava lugar ao ensino tecnicista especializado. (ARANHA, 2006, p.115). Essa divisão social proporcionada pela educação técnica constitui-se, segundo Santos (2019, p.49) como um dos maiores dilemas da pedagogia moderna. De um lado, há a necessidade de trabalhadores qualificados que necessitam de estudo e especialização. De outro, a questão de saber dosar instrução e qualificação, uma vez que a instrução ofertada ao trabalhador era aquela necessária à agilidade na reprodução, e não a formação geral do ser humano (SANTOS, 2019, p. 51).

Percebemos, desse modo, que a imbricação entre o progresso técnico e educação nos traz uma perspectiva complexa. Não podemos negar a técnica, tampouco ficarmos à margem do "fazer técnico" e sua fundamentação nas ciências da cibernética e automação, ou seja, não podemos furtar a educação de acompanhar o desenvolvimento da técnica em tecnologia. No entanto, é necessário estabelecer uma relação dialógica no sentido de compreendemos as tramas da técnica moderna.

Na sua concepção de técnica moderna, Heidegger apresenta as categorias de "verdade", "essência" e "ser". Essas categorias podem nos levar apressadamente a pensar uma possível perspectiva heideggeriana de educação como um castelo teórico sem efetividade. Para que esse equívoco não aconteça, é necessário interpretar e contextualizar esses conceitos no pensamento do autor. Heidegger não concebe a ideia de verdade como representação mental que adequa os entes arbitrariamente às designações humanas. A ideia de verdade, para Heidegger representa abertura histórica, aquilo que não pode ser apreendido em sua totalidade pela razão humana. Compreender a essência da técnica é compreender que, antes de significar progresso, ela significa o esquecimento da autenticidade da existência humana em seu sentido ontológico. Dito de outro modo, a existência em sentido ontológico é construção, é busca pelo constante desenvolvimento das possibilidades humanas em sua relação de reciprocidade e não de dominação sobre a natureza. De acordo com Heidegger:

Ser homem diz: ser como um mortal sobre essa terra. Diz habitar. A antiga palavra bauem (construir) diz que o homem é a medida que habita. A palavra bauem (construir), porém, significa ao mesmo tempo: proteger e cultivar, a

\begin{tabular}{|c|c|c|c|c|}
\hline Qonista Dialectus & Ano 10 & n. 23 & Maio - Agosto 2021 & p. $267-278$ \\
\hline
\end{tabular}


saber cultivar o campo, cultivar a vinha. Construir significa cuidar do crescimento que por si mesmo, dá tempo aos seus frutos. No sentido de proteger e cultivar, construir não é o mesmo que produzir (2008be, p. 127).

A reflexão de Heidegger sobre a modernidade nos permite perceber que a nossa existência não é pensada sob a forma de cultivo, mas de produção. A relação estabelecida entre ciência e sociedade, nesse aspecto, transforma-se radicalmente com a crescente mediação do capital. O modo de produção atual tende a ditar os rumos e a finalidade do conhecimento em detrimento de uma ação educativa mais abrangente, focada na liberdade e na criatividade dos seres humanos. As universidades perdem seu caráter de problematização e reflexão e passaram a adotar os critérios de previsibilidade e repetição. Junto com os avanços e as inúmeras facilidades, a técnica moderna trouxe ao humano a arrogância de conceber a realidade a partir de si mesmo, da sua representação subjetiva. Vejamos:

\footnotetext{
A ciência moderna é fundamentada também no fato de que o homem coloca a si mesmo como o sujeito determinante para o qual todo o ente pesquisável torna-se objeto. Isto, por sua vez, é baseado numa transformação da essência da verdade para a certeza, em consequência do que o ente verdadeiro assume o caráter de objetividade (HEIDEGGER, 2001, p. 121).
}

É essa compreensão mais radical sobre a questão da técnica que nos conduz a partir do mesmo lume a compreendermos a polarização social que ela realiza na educação. De um lado, aqueles que são detentores do conhecimento sobre a técnica e a tecnologia, isto é, o conhecimento técnico-científico. De outro modo, os que recebem uma educação técnica básica indispensável ao exercício da profissão. Esses últimos aprendem e desenvolvem um tipo de razão instrumental e operacional que enxerga na educação um meio para uma especialização profissional e não uma formação de sujeito integral. Diante dessa concepção, entendemos que não é propriamente a técnica moderna na sua configuração instrumental que reproduz a polarização social, mas é a própria racionalidade técnico-científica já presente entre os gregos que subverte a lógica da neutralidade técnica. Por trás dos dispositivos e instrumentos tecnológicos existe a vontade de controle e de dominação. Daí a educação ser um campo tão propício para a disseminação da visão de mundo da razão técnico-científica

A educação é a principal engrenagem de transformação social. Não obstante, quando é ideologicamente pensada a partir dos objetivos da sociedade burguesa ou capitalista, ela é reduzida a uma perspectiva pragmática e utilitarista do mundo. A técnica

\begin{tabular}{|l|l|l|l|l|}
\hline Govista Dialectus & Ano 10 & n. 23 & Maio - Agosto 2021 & p. 267 - 278 \\
\hline
\end{tabular}


moderna assim como a tecnologia é o que consolidam esse objetivo, pois, nesse contexto servem para reproduzir a desigualdade epistemológica e, por consequência, desigualdade social. Nesse sentido, “A expressão educação tecnológica, na atualidade, é uma das nomenclaturas apropriada pelas políticas públicas neoliberais para denominar as escolas profissionalizantes destinadas a classe trabalhadora." (SANTOS, 2019, p. 70).

A problematização proposta no artigo nos faz pensar acerca dos desafios, problemas e potencialidades da educação no Brasil. E antes que possamos articular com clareza alguma posição teórica, veem-se novamente as constantes transformações sociais que encontram na educação formal a legitimação do fracasso ou sucesso que os indivíduos podem obter. Essas transformações estão cada vez mais aceleradas após o desenvolvimento da técnica moderna e da tecnologia. O progresso técnico-científico trouxe mudanças decisivas para a sociedade, como por exemplo, as tecnologias da informação que modificou o modo como lidamos com os outros, com o conhecimento.

Por outro lado, é importante destacar que a modernidade trouxe, além do avanço técnico-científico, importantes contribuições teóricas no campo da pedagogia com pesquisas sobre propostas de alfabetização e sobre o papel da escola para o desenvolvimento de uma sociedade. Esses estudos não procuravam somente compreender a escola a partir de sua importância para os indivíduos, mas problematiza-la enquanto mecanismo de reprodução da desigualdade social. Um dos exemplos mais emblemáticos da reprodução de um statusquo é a dicotomia entre uma educação ampla que contemple a prática, mas também seu fundamento teórico e uma educação que procura formar mão de obra acrítica para uma sociedade.

Essa dicotomia é melhor compreendida quando aprofundamos alguns conceitos e ideias. Nesse sentido, realizamos um diálogo entre alguns pensadores, dentre eles, estão Heidegger e Deribaldo Santos. São pensadores de tempos e concepções singulares, porém, conversam entre si quando pensam a educação para além das determinações tecnicistas impostas pela modernidade. Compreender a essência da técnica moderna nos conduz invariavelmente a um feixe de conexões. Essas conexões nos permite discutir com mais propriedade o que entendemos por modernidade e como esta, na sua roupagem técnico-científica permeia e direciona a educação através das diretrizes tecnológicas. Contudo, é importante não perdermos de vista que a educação é também possibilidades. Do mesmo modo que a tecnologia ideologicamente pensada polariza a formação do sujeito entre saber intelectual e saber operacional traz em seu bojo a possibilidade de disseminação do conhecimento. A percepção das diversas

\begin{tabular}{|l|l|l|l|l|}
\hline Govista Dialectus & Ano 10 & n. 23 & Maio - Agosto 2021 & p. 267 - 278 \\
\hline
\end{tabular}


potencialidades do conhecimento técnico-científico e sua atuação no processo educativo são possíveis quando dialogamos com reflexões diversas, pois conseguimos enxergar quão amplo é o horizonte de perspectivas teóricas que nos levam e rever nossa prática.

\section{REFERÊNCIAS}

ARANHA, Maria Lúcia Arruda. Filosofia da educação. São Paulo: Moderna, 2006.

HEIDEGGER, Martin. A questão da técnica. In: ensaios e conferências. Trad. Emmanuel Carneiro Leão. Petrópolis: Vozes, 2008a.

Construir, habitar, pensar. In: ensaios e conferências. Trad. Márcia de Sá Cavalcante Schuback. Petrópolis: Vozes, 2008b. São Paulo: Abril cultural, 1983a. (Coleção os Pensadores).

O fim da filosofia e a tarefa do pensamento. In: Ensaios e conferências. Ernildo Stein.São Paulo: Abril cultural, 2008a.

. Que é Metafísica. Trad. Ernildo Stein. São Paulo: Abril cultural, 1983b (Coleção os pensadores)

Seminários de Zollikon. Editado por M. Boss. Trad. G Arnhold e M. F. Almeida Prado. Petrópolis: Vozes, 2001.

MANFREDI, Silvia Maria. Educação profissional no Brasil. São Paulo: Cortez, 2002.

SÁ, Franco Alexandre de. Heidegger e a essência da universidade. Covilhã: Lusosofia: press, 2008. (Coleção: artigos Lusosofia).

SANTOS, Deribaldo. Educação profissional: crise e precarização. São Paulo: Lutas anticapital, 2019.

\begin{tabular}{|l|l|l|l|l|}
\hline Govista Dialectus & Ano 10 & n. 23 & Maio - Agosto 2021 & p. 267 - 278 \\
\hline
\end{tabular}

